\title{
Association between lipid biomarkers and osteoporosis: a cross-sectional study
}

\author{
Bo Kan', Qianqian Zhao ${ }^{2}$, Lijuan Wang ${ }^{3}$, Shanshan Xue ${ }^{2}$, Hanqing Cai ${ }^{3^{*}}$ and Shuman Yang ${ }^{2^{*}}$ (D)
}

\begin{abstract}
Background: Osteoporosis and cardiovascular diseases (CVDs) are 2 major public health problems. Osteoporosis and CVDs may be linked but the association between lipid profile and osteoporosis is still controversial. The purpose of this study was to examine the associations of total cholesterol (TC), low-density lipoprotein cholesterol (LDL-C), high-density lipoprotein cholesterol (HDL-C) and triglyceride (TG) with osteoporosis.

Methods: Using inpatients' and outpatients' electronic medical records (EMR) and dual X-ray absorptiometry (DXA) database stored at The Second Hospital of Jilin University, we included 481 individuals with complete and valid lipid and bone mineral density (BMD) data in 2017. Serum samples were used to measure TC, LDL-C, HDL-C and TG. Femoral neck and total hip BMD were measured by DXA; osteoporosis was defined as femoral neck or total hip Tscore $\leq-2.5$. Multivariable logistic regression models were used to test the associations of TC, LDL-C, HDL-C and TG with osteoporosis.

Results: The mean age for included individuals was 62.7 years ( $S D=8.6$ years); $60.1 \%$ of them were female. Each standard deviation (SD) increase in TC (Odds Ratio [OR]: 1.48; $95 \%$ Confidence Interval [CI]: 1.06-2.07) and TG (OR: 1.67; $95 \%$ Cl: 1.16-2.39) were associated with increased risk of osteoporosis; LDL-C and HDL-C levels were not associated with osteoporosis. Age, sex and body mass index (BMI) did not interact with the relationships of TC and TG with osteoporosis (all $P>0.10$ ).
\end{abstract}

Conclusions: Higher TC and TG levels were associated with greater risk of osteoporosis in this cross-sectional study.

Keywords: Lipid biomarkers, Osteoporosis, Bone mineral density (BMD), Risk assessment

\section{Background}

Worldwide, osteoporosis and cardiovascular diseases (CVDs) are 2 major public health problems [1, 2]. Up to 49 million individuals have osteoporosis in North America, Europe, Japan, and Australia [3]. In 2017, CVDs lead to approximately 17.8 million deaths worldwide $[4,5]$. Osteoporosis and CVDs both significantly increase risk of morbidity and mortality $[6,7]$.

\footnotetext{
* Correspondence: caihanqing16@163.com; shumanyang@jlu.edu.cn ${ }^{3}$ Department of Endocrine, The Second Hospital of Jilin University, Jilin, Changchun, China

${ }^{2}$ Department of Epidemiology and Biostatistics, School of Public Health, Jilin University, 232-1163 Xinmin Street, Jilin 130021 Changchun, China Full list of author information is available at the end of the article
}

Osteoporosis and CVDs may be linked [8, 9]. Osteoporosis and CVDs share many risk factors, such as advancing age, premature menopause, genetics, a sedentary lifestyle and smoking, etc. [10, 11]. There is evidence suggesting that individuals with CVDs have 1.69 folds higher risk of osteoporosis than those without CVDs [12]. In addition, osteoporotic patients are 1.2 to 1.4 times more susceptible to cardiovascular events than those without osteoporosis $[10,13]$.

Lipid profile is useful for assessing risk of CVDs [14]. There is also vitro evidence suggesting lipids are involved in the development of osteoporosis [15].However, the association between lipid profile and osteoporosis in human studies is still controversial [16-25]. Majority of human studies suggested that there were negative

C The Author(s). 2021 Open Access This article is licensed under a Creative Commons Attribution 4.0 International License, which permits use, sharing, adaptation, distribution and reproduction in any medium or format, as long as you give appropriate credit to the original author(s) and the source, provide a link to the Creative Commons licence, and indicate if changes were made. The images or other third party material in this article are included in the article's Creative Commons licence, unless indicated otherwise in a credit line to the material. If material is not included in the article's Creative Commons licence and your intended use is not permitted by statutory regulation or exceeds the permitted use, you will need to obtain permission directly from the copyright holder. To view a copy of this licence, visit http://creativecommons.org/licenses/by/4.0/ The Creative Commons Public Domain Dedication waiver (http://creativecommons.org/publicdomain/zero/1.0/) applies to the data made available in this article, unless otherwise stated in a credit line to the data. 
associations between lipid biomarkers and bone mineral density (BMD) [16, 17, 19, 22-25]. However, Ersoy et al. [18] and Lahon et al. [20] found that low-density lipoprotein cholesterol (LDL-C) was positively correlated with BMD. Ghadiri-Anari et al. [21] suggested a null association between lipids and BMD. Because of the conflicting associations of lipids with BMD and/or osteoporosis, we examined the associations of total cholesterol (TC), LDL-C, high-density lipoprotein cholesterol (HDL-C) and triglyceride (TG) with osteoporosis in a Chinese hospital-based population.

\section{Methods}

\section{Study setting and subjects}

The data were drawn from inpatients' and outpatients' electronic medical records (EMR) and dual X-ray absorptiometry (DXA) database stored at The Second Hospital of Jilin University, which is a major diagnosis and treatment center for severe diseases (i.e., cancers and CVDs) in northeast China. The linked for EMR and DXA databases capture inpatients' and outpatients' demographics (i.e., age and sex), anthropometry data (e.g., body height and weight), clinical laboratory measurement records, prescription drug dispensation records, clinical diagnoses and BMD data.

We identified individuals with complete and valid data on femoral neck and total hip BMD, TC, LDL-C, HDL$\mathrm{C}$ and TG in 2017 in this study. We excluded individuals: (1) with age $<50$ years old at BMD test; (2) with early (<40 years) menopause; (3) with a lipid-lowering therapy, synthyroid or hormone-replacement therapy; (4) with osteoporosis-related diseases such as cancer, thyroid disease, hypopituitarism, rheumatoid arthritis, chronic renal failure or renal dysfunction (creatinine > $442 \mu \mathrm{mol} / \mathrm{L}$ ), chronic liver disease or liver dysfunction (aspartate aminotransferase or alanine aminotransferase $>80 \mathrm{U} / \mathrm{L}$ ); (5) with a surgical history of bilateral salpingo-oophorectomy menopause or a history of bone surgery at the lumbar spine or hip. There are no data on osteoporosis medications in our study. Osteoporosis medications are prescribed after the patients are diagnosed with osteoporosis through DXA testing. To partially excluding the individuals taking anti-osteoporosis medication, we only include individuals at their first DXA tests in our study. This study was approved by The Second Hospital of Jilin University Life Science Ethics Committee (2017 Research Approval No.13).

\section{BMD measurement}

Femoral neck and total hip BMD were measured by a DXA fan-beam bone densitometer (Discovery Wi, Hologic, Bedford, MA, USA). The control spine phantom scan performed each day had a long-term (more than 5 years) coefficient of variation (CV) of $<0.5 \%$. A BMD Tscore was calculated using the following formula:

$$
\mathrm{T}=\left(\mathrm{X}-\mu^{\text {reference }}\right) / \mathrm{SD}^{\text {reference }}
$$

Where $\mathrm{X}=$ the observed BMD of the patients, $\mu^{\text {refer- }}$ ence $=\mathrm{BMD}$ in young adults, and $\mathrm{SD}^{\text {reference }}=$ standard deviation of BMD in young adults.

We defined osteoporosis as femoral neck or total hip $\mathrm{T}$-score $\leq-2.5[26]$; the reference for calculating $\mathrm{T}$-score was based on BMD data from Whites 20-29 years old in the third National Health and Nutrition Examination Survey (NHANES III) [27].

\section{Blood draw and storage}

Fasting blood samples ( $\geq 8 \mathrm{~h}$ ) were drawn from individuals with spray-coated silica and a polymer gel evacuated sterile collection tubes (BD, Becton, Dickinson and Company, Franklin Lakes, New Jersey, USA) by nurses; these blood samples were centrifuged to obtain serum at clinical laboratory department.

\section{Lipid biomarkers ascertainment}

Within $2 \mathrm{~h}$ following blood draw, serum samples were used to directly measure TC, LDL-C, HDL-C and TG; their levels were determined by a biochemical analyzer (7600 model, Hitachi, Tokyo, Japan). The CVs for TC, LDL-C, HDL-C and TG measurements were $2.5 \%$, $3.1 \%, 5.1$ and $1.9 \%$, respectively.

\section{Covariate ascertainment}

The covariates were extracted from EMR and DXA databases. The covariates for this study included age, sex, body mass index (BMI), disease diagnoses (e.g., type 2 diabetes, hypertension, ischemic heart disease, ischemic stroke, osteoarthritis), diabetes complications (e.g., neuropathy, retinopathy, nephropathy), diabetes medications (e.g., insulin, biguanide, sulfonylureas, others), antihypertension medications (e.g., calcium channel blockers, angiotensin 2 receptor blockers, beta-blockers, diuretics, angiotensin converting enzyme inhibitors), liver function biomarkers, bone biochemical markers (e.g., alkaline phosphatase, calcium and phosphorus), thyroid function biomarkers and glucose metabolic biomarkers. The covariates included in the analysis could be potential confounders or effect modifiers that maybe associated with lipid biomarkers and femoral neck or total hip BMD [16, $22,24]$. Height and weight were measured using a wallmounted stadiometer (to the nearest $0.1 \mathrm{~cm}$ ) and an electronic scale (to the nearest $0.1 \mathrm{~kg}$ ). BMI was calculated as weight (kilograms) divided by the square of the height (meters). Any past use of diabetes medications and antihypertension medications were self-reported. 
Disease diagnoses were either self-reported and/or clinically diagnosed based on specific criteria. The biomarkers were measured using established methods in the clinical setting [28]. To further examine whether menopausal age had an impact on the association between lipid biomarkers and osteoporosis, we also considered self-reported menopausal age in women.

\section{Statistical analysis}

Multivariable logistic regression models were used to test the associations of TC (per SD increase), LDL-C (per SD increase), HDL-C (per SD increase) and TG (per SD increase) with osteoporosis. Due to the high correlations between lipid biomarkers (Pearson $r$ up to 0.70 ), we included each lipid biomarker in one model. Models were further adjusted for sex, age, BMI, type 2 diabetes, neuropathy, biguanide, calcium channel blockers, angiotensin converting enzyme inhibitors, alanine transaminase, albumin, total bilirubin and alkaline phosphatase; variables considered but not included in the adjusted model were hypertension, ischemic heart disease, ischemic stroke, osteoarthritis, retinopathy, nephropathy, insulin, sulfonylureas, others, angiotensin 2 receptor blockers, beta-blockers, diuretics, aspartate aminotransferase, total protein, gamma-glutamyltransferase, calcium, phosphorus, free thyroxine 4, thyroidstimulating hormone, glycated hemoglobin A1c and fasting glucose, because they failed to meet $P<0.10$ criteria under bivariate analyses with osteoporosis. Because total bilirubin and direct bilirubin are highly associated $(r=0.80)$, to avoid the effect of collinearity, direct bilirubin was not included in the multivariable logistic regression models.

Multivariable linear regression models were used to test the associations between lipid biomarkers and femoral neck or total hip BMD. Variables included in the model were the same as above.

TC, LDL-C, HDL-C and TG were classified as normal and abnormal groups according to their clinical reference values. In serum, $\mathrm{TC} \geq 5.20 \mathrm{mmol} / \mathrm{L}$ and/or LDL$\mathrm{C} \geq 3.40 \mathrm{mmol} / \mathrm{L}$ and/or HDL-C $<1.00 \mathrm{mmol} / \mathrm{L}$ and/or TG $\geq 1.70 \mathrm{mmol} / \mathrm{L}$ were defined as abnormal groups [29]. Multivariable logistic regression models were used to test the associations of each lipid biomarker group with osteoporosis. Again, adjusted covariates were the same as above.

Multivariable logistic regression models were used to test the associations of each lipid biomarker group with osteoporosis in women only and in individuals with any chronic disorders. In the subgroup analysis of women only, we further adjusted menopausal age in addition to the covariates as mentioned above.

All analyses were conducted with SPSS (version 24.0, IBM, Inc., New York, USA).

Patients with complete and valid bone mineral density (BMD) and lipid data in $2017(\mathrm{~N}=718)$

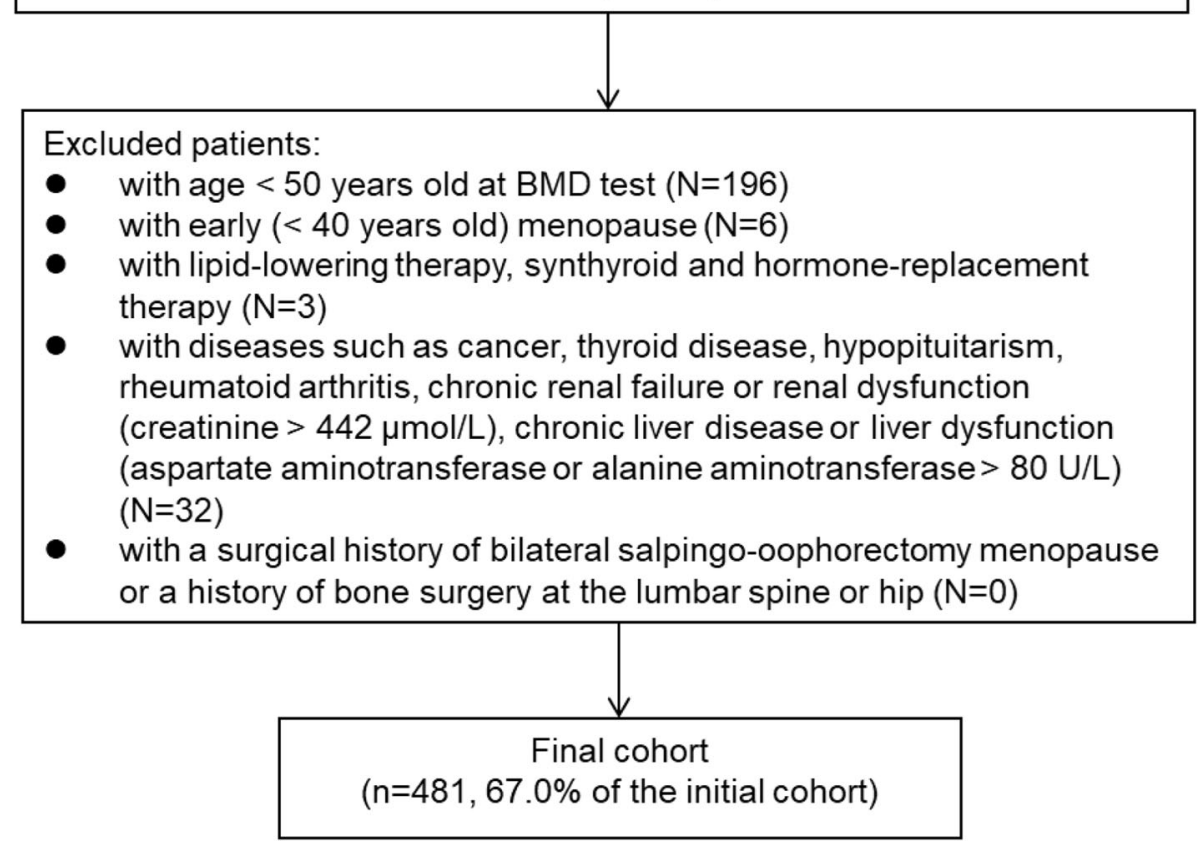

Fig. 1 Flow chart for cohort inclusion and exclusions 
Table 1 Characteristics of study participants by osteoporosis status

\begin{tabular}{|c|c|c|c|}
\hline Variable & No Osteoporosis $(n=411)$ & Osteoporosis $(n=70)$ & $P$ \\
\hline \multicolumn{4}{|l|}{ Demographics } \\
\hline Female $(n, \%)^{b}$ & $224(54.5)$ & $65(92.9)$ & $<0.001$ \\
\hline Age (years) & $61.5(8.0)$ & $70.1(8.4)$ & $<0.001$ \\
\hline \multicolumn{4}{|l|}{ Anthropometry } \\
\hline Height (cm) & $162.8(8.6)$ & $153.7(5.8)$ & $<0.001$ \\
\hline Weight (kg) & $68.9(11.4)$ & $57.1(9.3)$ & $<0.001$ \\
\hline Body mass index $\left(\mathrm{kg} / \mathrm{m}^{2}\right)$ & $26.0(3.4)$ & $24.2(3.8)$ & $<0.001$ \\
\hline \multicolumn{4}{|l|}{ Disease diagnosis $(n, \%)^{b}$} \\
\hline Type 2 diabetes & 317 (76.39) & $40(60.61)$ & 0.007 \\
\hline Hypertension & $198(47.71)$ & $30(45.45)$ & 0.733 \\
\hline Ischemic heart disease & $70(16.87)$ & $14(21.21)$ & 0.388 \\
\hline Ischemic stroke & $10(2.41)$ & $3(4.55)$ & 0.320 \\
\hline Osteoarthritis & $6(1.45)$ & $1(1.52)$ & 0.965 \\
\hline \multicolumn{4}{|l|}{ Diabetes complication $(n, \%)^{b}$} \\
\hline Neuropathy & $199(48.42)$ & $26(37.14)$ & 0.082 \\
\hline Retinopathy & $104(25.30)$ & $16(22.86)$ & 0.662 \\
\hline Nephropathy & $7(1.69)$ & $2(3.03)$ & 0.454 \\
\hline \multicolumn{4}{|l|}{ Diabetes medication $(n, \%)^{b}$} \\
\hline Insulin & $178(43.3)$ & $28(40.0)$ & 0.605 \\
\hline Biguanide & $75(18.3)$ & $5(7.1)$ & 0.027 \\
\hline Sulfonylureas & $27(6.6)$ & $6(8.6)$ & 0.541 \\
\hline Others & $22(5.4)$ & $5(7.1)$ & 0.548 \\
\hline \multicolumn{4}{|l|}{ Antihypertension medication $(n, \%)^{b}$} \\
\hline Calcium channel blockers & $34(8.27)$ & $11(15.71)$ & 0.048 \\
\hline Angiotensin 2 receptor blockers & $22(5.35)$ & $3(4.29)$ & 0.710 \\
\hline Beta-blockers & $9(2.19)$ & $2(2.86)$ & 0.730 \\
\hline Diuretics & $6(1.46)$ & $1(1.43)$ & 0.984 \\
\hline Angiotensin converting enzyme inhibitors & $2(0.49)$ & $2(2.86)$ & 0.044 \\
\hline \multicolumn{4}{|l|}{ Lipid biomarker } \\
\hline Total cholesterol (mmol/L) & $5.06(1.26)$ & $5.42(1.35)$ & 0.028 \\
\hline Low-density lipoprotein cholesterol (mmol/L) & $2.85(0.86)$ & $3.04(0.99)$ & 0.101 \\
\hline High-density lipoprotein cholesterol (mmol/L) & $1.14(0.31)$ & $1.19(0.31)$ & 0.235 \\
\hline Triglyceride $(\mathrm{mmol} / \mathrm{L})^{\mathrm{a}}$ & $1.57(1.12,2.44)$ & $1.83(1.27,3.05)$ & 0.189 \\
\hline \multicolumn{4}{|l|}{ Liver function biomarker } \\
\hline Alanine transaminase $(U / L)^{a}$ & $21.00(15.00,30.00)$ & $16.50(11.00,22.00)$ & 0.008 \\
\hline Aspartate aminotransferase $(\mathrm{U} / \mathrm{L})^{\mathrm{a}}$ & $18.00(15.00,23.00)$ & $17.00(15.00,22.00)$ & 0.420 \\
\hline Total protein (g/L) & $71.35(6.47)$ & $70.32(8.17)$ & 0.242 \\
\hline Albumin (g/L) & $43.10(4.21)$ & $41.12(5.32)$ & $<0.001$ \\
\hline Total bilirubin ( $\mu \mathrm{mol} / \mathrm{L})$ & $13.10(5.54)$ & $11.51(5.15)$ & 0.027 \\
\hline Direct bilirubin $(\mu \mathrm{mol} / \mathrm{L})^{\mathrm{a}}$ & $3.25(2.27,4.49)$ & $2.60(1.90,3.99)$ & 0.092 \\
\hline Gamma-glutamyltransferase $(\mathrm{U} / \mathrm{L})^{\mathrm{a}}$ & $27.00(20.00,43.00)$ & $20.00(15.00,33.00)$ & 0.452 \\
\hline \multicolumn{4}{|l|}{ Bone biochemical marker } \\
\hline Alkaline phosphatase (U/L) & $89.75(28.98)$ & $108.20(51.70)$ & $<0.001$ \\
\hline Calcium (mmol/L) & $2.34(0.13)$ & $2.31(0.15)$ & 0.170 \\
\hline
\end{tabular}


Table 1 Characteristics of study participants by osteoporosis status (Continued)

\begin{tabular}{|c|c|c|c|}
\hline Variable & No Osteoporosis $(n=411)$ & Osteoporosis $(n=70)$ & $P$ \\
\hline Phosphorus (mmol/L) & $1.13(0.20)$ & $1.12(0.21)$ & 0.625 \\
\hline \multicolumn{4}{|l|}{ Thyroid function biomarker } \\
\hline Free thyroxine 4 (Ft4)(pmol/L) & $15.94(3.15)$ & $16.36(11.45)$ & 0.575 \\
\hline Thyroid-stimulating hormone $(\mathrm{TSH})(\mathrm{mIU} / \mathrm{L})^{\mathrm{a}}$ & $2.03(1.23,3.11)$ & $1.98(0.96,3.74)$ & 0.881 \\
\hline \multicolumn{4}{|l|}{ Glucose metabolic biomarker } \\
\hline Glycated hemoglobin A1c (\%) & $8.96(2.10)$ & $8.45(2.25)$ & 0.112 \\
\hline Fasting glucose (mmol/L) & $9.20(3.76)$ & $8.63(5.04)$ & 0.301 \\
\hline
\end{tabular}

Continuous variables with normal distribution are shown as means (standard deviations)

${ }^{a}$ continuous variables with skewed distribution are shown as medians (inter-quartile ranges)

${ }^{\mathrm{b}}$ categorical variables are shown as frequencies (\%)

\section{Results}

After excluding ineligible individuals (Fig. 1), we included 481 individuals for this study. As compared to excluded individuals, included individuals were older $(62.7 \pm 8.6$ vs. $45.2 \pm 10.1$ years; $P<0.001)$ and more likely to be female (60.1 vs. $49.0 \% ; P<0.001)$; BMI was not significantly different between included and excluded individuals $\left(25.7 \pm 3.5\right.$ vs. $25.7 \pm 4.3 \mathrm{~kg} / \mathrm{m}^{2} ; P=$ $0.886)$. We only had menopausal age for 234 women ( $81.0 \%$ of all women included in this study). Based on the women with complete data on menopausal age, we found that women with osteoporosis had younger menopausal age than those without osteoporosis $(47.7 \pm 3.5$ vs. $49.4 \pm 3.2$ years; $P<0.001)$.

Among included individuals, 357 (74.2\%), 228 (47.4\%) and $84(17.5 \%)$ individuals had type 2 diabetes, hypertension and ischemic heart disease diagnoses, respectively. The mean age for included individuals was 62.7 years ( $\mathrm{SD}=8.6$ years); $60.1 \%$ of individuals were female; the average BMI for included individuals was $25.7 \mathrm{~kg} / \mathrm{m}^{2}$ $\left(\mathrm{SD}=3.5 \mathrm{~kg} / \mathrm{m}^{2}\right)$. As shown in Table 1, osteoporotic individuals tended to be older, more likely to be female and had higher proportion of calcium channel blockers medication, angiotensin converting enzyme inhibitors medication, higher levels of TC, alkaline phosphatase and a lower proportion of type 2 diabetes, biguanide medication, lower levels of BMI, alanine transaminase, albumin and total bilirubin.

As shown in Table 2, among all 481 individuals, in the adjusted model, each SD increase in TC (Odds Ratio [OR]: 1.48; $95 \%$ Confidence Interval [CI]: 1.06-2.07) and TG (OR: 1.67; $95 \% \mathrm{CI}: 1.16-2.39$ ) were associated with increased risk of osteoporosis; LDL-C and HDL-C levels were not associated with osteoporosis. Age, sex and BMI did notmodify the relationships of TC and TG with osteoporosis (all $P>0.10$ ). When T-score of BMD was treated as continuous variable, we observed similar trends of associations of TC and TG with BMD T-score though these associations did not reach statistical significance (Table S1). After classifying lipid biomarkers according to their clinical cut-off values, we found abnormal higher TG levels in serum were associated with higher risk of osteoporosis (Table S2). In women, after further adjusting menopausal age, we found that TG was still significantly associated with osteoporosis (OR: 1.98; $95 \%$ CI: 1.24-3.17; Table S3). In the subgroup analysis of individuals with any chronic disorders, we also found elevated TC and TG levels were associated with higher risk of osteoporosis (Table S4).

\section{Discussion}

In this study of individuals aged $\geq 50$ years, we demonstrated that higher TC and TG levels were associated with greater risk of osteoporosis. Serum LDL-C and HDL-C levels were not associated with osteoporosis.

The positive relationships of TC and TG levels with osteoporosis in our study are consistent with some previous studies $[19,23,25,30]$, in which there were positive correlations of TC and TG levels with osteoporosis. We found no significant associations of HDL-C and LDL-C with osteoporosis. These results are also in line with the findings reported by Ghadiri-Anari A et al. [21], those found insignificant associations between lipids and BMD. However, existing epidemiological studies suggested that there are still conflicting associations of HDL-C and LDL-C with osteoporosis [17, 18, 20]. These conflicting results are likely attributed to the different

Table 2 Adjusted $^{\mathrm{a}}$ odds ratio (ORs) and $95 \%$ confidence intervals (95\% Cls) for osteoporosis associated with lipid biomarkers (per standard deviation increase)

\begin{tabular}{lll}
\hline Independent Variable & $\boldsymbol{P}$ & OR (95 \%Cl) \\
\hline Total cholesterol & 0.022 & $1.48(1.06-2.07)$ \\
Low-density Lipoprotein cholesterol & 0.108 & $1.29(0.95-1.76)$ \\
High-density Lipoprotein cholesterol & 0.547 & $1.11(0.79-1.56)$ \\
Triglyceride & 0.005 & $1.67(1.16-2.39)$
\end{tabular}

${ }^{a}$ Adjusted for sex, age, body mass index, type 2 diabetes, neuropathy, biguanide, calcium channel blockers, angiotensin converting enzyme inhibitors, alanine transaminase, albumin, total bilirubin and alkaline phosphatase 
study sample sizes, study populations and covariates adjusted in the study. For example, the insignificant association between LDL-C and osteoporosis in our study may be a false negative finding due to the limited sample size. In addition, numerous studies suggested that different study populations may lead to different results $[16,22$, 23]. Majority of included individuals $(82.5 \%)$ in our study had chronic diseases (i.e., type 2 diabetes, hypertension and ischemic heart disease). These diseases were suggested to be related to lipids and osteoporosis [3133]. However, most of the studies on the association between lipids and osteoporosis were based on generally healthy populations $[22,25,34]$. This may lead to conflicting results. Lastly, as compared to previous studies $[16,21,24]$, they used different covariates to adjusting the association between lipids and osteoporosis. This may also cause inconsistent results between studies.

Regardless of consistent or conflicting findings, the positive associations of TC and TG levels with BMD can be explained by several biological mechanisms. First, the nuclear hormone receptor peroxisome proliferator activated receptor $\gamma$ (PPAR $\gamma$ ) may play a role in the relationship of lipid biomarkers and BMD. PPAR $\gamma$ can be activated by lipid metabolites. When PPAR $\gamma$ level increases, osteogenesis is inhibited [35]; this leads to increased bone loss. Second, higher lipid levels are associated with an increase in oxidized lipids and higher oxidative stress levels. Higher oxidative stress level could inhibit osteoblast differentiation as well as to promote adipocyte differentiation [36, 37]. Third, higher serum TG levels are positively associated with higher bone marrow fat [38], which leads to lower trabecular BMD [39].

Our study has some strengths. DXA was used to diagnose osteoporosis. In addition, the lipid biomarkers (e.g., TC, LDL-C, HDL-C, TG) were measured using established methods in the clinical setting [40]. This ensured the reliability and accuracy of osteoporosis ascertainment and lipid measurements, which allowed us to analyzing the associations between lipids and osteoporosis with less bias. Several limitations for this study are acknowledged. First, the findings were derived from a cross-sectional study. Therefore, we cannot make causal inference about the association between lipid biomarkers and BMD. Second, we only analyzed some inpatients and outpatients in The Second Hospital of Jilin University. For example, $74.2 \%$ of individuals in our study were type 2 diabetic patients, while the prevalence of type 2 diabetes in Jilin Province is $17.5 \%$ [41]. Thus, the findings from this selected population may not be able to generalize to general population or the population in the hospital. Last, due to the absent data, we did not consider individuals' lifestyle factors (i.e., smoking and alcohol use and physical activity) and vitamin D levels.
However, in a previous study, adjustment of vitamin D levels did not appreciably change the associations of TC and TG with osteoporosis [42].

\section{Conclusions}

In conclusion, there were associations between serum TC and TG and osteoporosis in this study. These findings extended our understanding about the lipid profile and BMD. High quality prospective studies on relationship between lipid biomarkers and BMD are still warranted to confirm or oppose our results.

\section{Abbreviations}

CVDs: Cardiovascular diseases; TC: Total cholesterol; LDL-C: Low-density lipoprotein cholesterol; HDL-C: High-density lipoprotein cholesterol; TG: Triglyceride; EMR: Electronic medical records; DXA: Dual X-ray absorptiometry; BMD: Bone mineral density; SD: Standard deviation; OR: Odds ratio; Cl: Confidence interval; BMI: Body mass index; NHANES III: The third National Health and Nutrition Examination Survey; SDs: Standard deviations;

PPARY: Peroxisome proliferator activated receptor $\gamma$

\section{Supplementary Information}

The online version contains supplementary material available at https://doi. org/10.1186/s12891-021-04643-5.

Additional file 1: Table S1. Multivariable linear regression analysis* of the associations between lipid biomarkers and T-score of femoral neck and total hip bone mineral density (BMD). Table S2. Adjusted* odds ratio (ORs) and 95\% confidence intervals (95\% Cls) for osteoporosis associated with abnormal lipid biomarkers. Table S3. Adjusted* odds ratio (ORs) and 95\% confidence intervals (95\% Cls) for osteoporosis in women associated with lipid biomarkers (per standard deviation increase). Table S4. Adjusted* odds ratio (ORs) and $95 \%$ confidence intervals (95\% Cls) for osteoporosis associated with lipid biomarkers (per standard deviation increase) in patients with chronic disorders

\section{Acknowledgements}

Not applicable.

\section{Authors' contributions}

BK conceived the study and wrote the original draft. QQZ and LJW contributed in data curation. SSX will be responsible for statistical analyses. HQC contributed in writing draft and editing. SMY contributed in the conception, interpretation of data and revisions of article. All authors read and approved the final manuscript.

\section{Funding}

There was no funding or support for this study.

\section{Availability of data and materials}

The datasets used and analysed during the current study are available from the corresponding author on reasonable request.

\section{Declarations}

Ethics approval and consent to participate

This investigation was approved by The Second Hospital of Jilin University Life Science Ethics Committee (Ethic approval code: 2017 Research Approval No.13). The content is solely the responsibility of the authors and does not represent the official views of The Second Hospital of Jilin University. Written informed consent was obtained for all participants.

Consent for publication

Not applicable. 


\section{Competing interests}

The authors declare that they have no competing interests.

\section{Author details}

'Department of Clinical Laboratory, The Second Hospital of Jilin University, Jilin, Changchun, China. ${ }^{2}$ Department of Epidemiology and Biostatistics, School of Public Health, Jilin University, 232-1163 Xinmin Street, Jilin 13002 Changchun, China. ${ }^{3}$ Department of Endocrine, The Second Hospital of Jilin University, Jilin, Changchun, China.

\section{Received: 12 October 2020 Accepted: 23 August 2021} Published online: 06 September 2021

\section{References}

1. Compston JE, McClung MR, Leslie WD, Osteoporosis. Lancet. 2019; 393(10169):364-76

2. Laslett LJ, Alagona P Jr, Clark BA 3rd, Drozda JP Jr, Saldivar F, Wilson SR, Poe C, Hart M. The worldwide environment of cardiovascular disease: prevalence, diagnosis, therapy, and policy issues: a report from the American College of Cardiology. J Am Coll Cardiol. 2012;60(25 Suppl):1-49.

3. Wade SW, Strader C, Fitzpatrick LA, Anthony MS, O'Malley CD. Estimating prevalence of osteoporosis: examples from industrialized countries. Arch Osteoporos. 2014;9:182.

4. Collaborators GCoD. Global, regional, and national age-sex-specifc mortality for 282 causes of death in 195 countries and territories, 1980-2017: a systematic analysis for the Global Burden of Disease Study 2017. Lancet. 2018;392:1736-88

5. Collaborators GDaH. Global, regional, and national disability-adjusted lifeyears (DALYs) for 359 diseases and injuries and healthy life expectancy (HALE) for 195 countries and territories, 1990-2017: a systematic analysis for the Global Burden of Disease Study 2017. The Lancet. 2018;392(10159): 1859-922.

6. Liu SW, Li YC, Zeng XY. Burden of cardiovascular diseases in china, 19902016 findings from the 2016 global burden of disease study. JAMA Cardiol. 2019;4(4):342-52

7. Yu F, Xia W. The epidemiology of osteoporosis, associated fragility fractures, and management gap in China. Arch Osteoporos. 2019:14(32):1-20.

8. Buizert PJ, van Schoor NM, Lips P, Deeg DJ, Eekhoff EM. Lipid levels: a link between cardiovascular disease and osteoporosis? J Bone Miner Res. 2009. 24(6):1103-9.

9. Tanko LB, Christiansen C, Cox DA, Geiger MJ, McNabb MA, Cummings SR. Relationship between osteoporosis and cardiovascular disease in postmenopausal women. J Bone Miner Res. 2005;20(11):1912-20.

10. Laroche M, Pecourneau V, Blain H, Breuil V, Chapurlat R, Cortet B, Sutter B, Degboe Y. committee Gs: Osteoporosis and ischemic cardiovascular disease. Joint Bone Spine. 2017:84(4):427-32.

11. Lello S, Capozzi A, Scambia G. Osteoporosis and cardiovascular disease: an update. Gynecol Endocrinol. 2015:31(8):590-4.

12. Murray MK, Bode K, Whittaker P. Gender-specific associations between coronary heart disease and other chronic diseases: cross-sectional evaluation of national survey data from adult residents of Germany. J Geriatr Cardiol. 2019:16(9):663-70.

13. Uyl DD, Nurmohamed MT, Tuyl LH, Raterman HGR, Lems WF. (Sub)clinical cardiovascular disease is associated with increased bone loss and fracture risk; a systematic review of the association between cardiovascular disease and osteoporosis. Arthritis Res Ther. 2011;13(1):R5.

14. Collaboration TERF. Lipid-related markers and cardiovascular disease prediction. JAMA. 2012;307(23):2499-506.

15. Parhami F, Tintut $Y$, Beamer WG, Gharavi N, Goodman W, Demer LL. Atherogenic high-fat diet reduces bone mineralization in mice. J Bone Miner Res. 2001;16(1):182-8.

16. Panahi N, Soltani A, Ghasem-Zadeh A, Shafiee G, Heshmat R, Razi F, Mehrdad N, Nabipour I, Larijani B, Ostovar A. Associations between the lipid profile and the lumbar spine bone mineral density and trabecular bone score in elderly Iranian individuals participating in the Bushehr Elderly Health Program: a population-based study. Arch Osteoporos. 2019;14(1):52.

17. Yazdanpanah MH, Sedighi S, Rajabi MR, Osati S, Dehghan A, Ehrampoush E, Alipoor R, Homayounfar R. Lipid profiles as a possible contributor to osteoporosis. Gazi Med J. 2018;29(3):191-5.
18. Ersoy GS, Simsek EE, Vatansever D, Kasikci HO, Keser B, Sakin O. Lipid profile and plasma atherogenic index in postmenopausal osteoporosis. North Clin Istanb. 2017:4(3):237-41.

19. Orozco P. Atherogenic lipid profile and elevated lipoprotein (a) are associated with lower bone mineral density in early postmenopausal overweight women. Eur J Epidemiol. 2004;19(12):1105-12.

20. Lahon D, Borgohain M, Thakur BB. A correlative study on serum lipid profile and osteogenic mineral status in osteoporosis. J Evol Med Dent Sci. 2016; 5(23):1243-50.

21. Ghadiri-Anari A, Mortezaii-Shoroki Z, Modarresi M, Dehghan A. Association of lipid profile with bone mineral density in postmenopausal women in Yazd province. Int J Reprod Biomed (Yazd). 2016;14(9):597-602.

22. Cui RT, Zhou L, Li ZH, Li Q, Oi ZM, Zhang JY. Assessment risk of osteoporosis in Chinese people: relationship among body mass index, serum lipid profiles, blood glucose, and bone mineral density. Clin Interv Aging. 2016;11:887-95

23. Bijelic R, Balaban J, Milicevic S. Correlation of the Lipid Profile, BMI and Bone Mineral Density in Postmenopausal Women. Mater Sociomed. 2016;28(6): $412-5$.

24. Li S, Guo H, Liu Y, Wu F, Zhang H, Zhang Z, Xie Z, Sheng Z, Liao E. Relationships of serum lipid profiles and bone mineral density in postmenopausal Chinese women. Clin Endocrinol. 2015;82(1):53-8.

25. Jeong TD, Lee W, Choi SE, Kim JS, Kim HK, Bae SJ, Chun S, Min WK. Relationship between serum total cholesterol level and serum biochemical bone turnover markers in healthy pre- and postmenopausal women. Biomed Res Int 2014:2014:398397.

26. Kanis JA, Melton LJ, Christiansen C, Johnston CC, Khaltaev N. The diagnosis of osteoporosis. J Bone Miner Res. 1994;9(8):1137-41.

27. Looker AC, Wahner HW, Dunn WL, Calvo MS, Harris TB, Heyse SP, Johnston CC Jr, Lindsay R. Updated data on proximal femur bone mineral levels of US adults. osteoporos Int. 1998:8:468-89.

28. Infusino I, Frusciante E, Braga F, Panteghini M. Progress and impact of enzyme measurement standardization. Clin Chem Lab Med. 2017:55(3):334-

29. Joint Committee issued Chinese guideline for the management 0 , dyslipidemia in a. 2016 Chinese guideline for the management of dyslipidemia in adults. Zhonghua Xin Xue Guan Bing Za Zhi. 2016;44(10): 833-53.

30. Chen Z, Zhao GH, Zhang YK, Shen GS, Xu YJ, Xu NW. Research on the correlation of diabetes mellitus complicated with osteoporosis with lipid metabolism, adipokines and inflammatory factors and its regression analysis. Eur Rev Med Pharmaco. 2017:21:3900-5.

31. Betteridge DJ. Lipids and atherogenesis in diabetes mellitus. Atherosclerosis. 1996;124(Suppl):43-7.

32. Kurra S, Fink DA, Siris ES. Osteoporosis-associated Fracture and Diabetes. Endocrinol Metab Clin North Am. 2014;43(1):233-+

33. Ivanovic B, Tadic M. Hypercholesterolemia and hypertension: two sides of the same coin. Am J Cardiovasc Drugs. 2015;15(6):403-14.

34. Jeong IK, Cho SW, Kim SW, Choi HJ, Park KS, Kim SY, Lee HK, Cho SH, Oh $\mathrm{BH}$, Shin CS. Lipid profiles and bone mineral density in pre- and postmenopausal women in Korea. Calcif Tissue Int. 2010;87(6):507-12.

35. Nuttall ME, Gimble JM. Controlling the balance between osteoblastogenesis and adipogenesis and the consequent therapeutic implications. Curr Opin Pharmacol. 2004;4(3):290-4.

36. Yamaguchi T, Sugimoto $T$, Yano S, Yamauchi M, Sowa H, Chen QX, Chihara K. Plasma lipids and osteoporosis in postmenuposal women. Endocr J. 2002; 49(2):211-7

37. Parhami F, Jackson SM, Tintut $Y$, Le $V$, Balucan JP, Territo M, Demer LL. Atherogenic Diet and Minimally Oxidized Low Density Lipoprotein Inhibit Osteogenic and Promote Adipogenic Differentiation of Marrow Stromal Cells. J Bone Miner Res. 1999;14(12):2067-78.

38. Bredella MA, Gill CM, Gerweck AV, Landa MG, Kumar V, Daley SM, Torriani M, Miller KK. Ectopic and serum lipid levels are positively associated with bone marrow fat in obesity. Radiology. 2013;269(2):534-41.

39. Schwartz AV, Sigurdsson S, Hue TF, Lang TF, Harris TB, Rosen CJ, Vittinghoff $E$, Siggeirsdottir $\mathrm{K}$, Sigurdsson G, Oskarsdottir D, et al. Vertebral bone marrow fat associated with lower trabecular BMD and prevalent vertebral fracture in older adults. J Clin Endocrinol Metab. 2013;98(6):2294-300.

40. Bachorik PS. Measurement of total cholesterol, HDL-cholesterol, and LDLcholesterol. Clin Lab Med. 1989;9(1):61-72. 
41. Wang S, Ungvari GS, Forester BP, Chiu HFK, Wu Y, Kou C, Fu Y, Qi Y, Liu Y, Tao $Y$, et al. Gender differences in general mental health, smoking, drinking and chronic diseases in older adults in Jilin province, China. Psychiatry Res. 2017:251:58-62.

42. Garg MK, Marwaha RK, Tandon N, Bhadra K, Mahalle N. Relationship of lipid parameters with bone mineral density in Indian population. Indian J Endocrinol Metab. 2014;18(3):325-32.

\section{Publisher's Note}

Springer Nature remains neutral with regard to jurisdictional claims in published maps and institutional affiliations.

Ready to submit your research? Choose BMC and benefit from:

- fast, convenient online submission

- thorough peer review by experienced researchers in your field

- rapid publication on acceptance

- support for research data, including large and complex data types

- gold Open Access which fosters wider collaboration and increased citations

- maximum visibility for your research: over $100 \mathrm{M}$ website views per year

At BMC, research is always in progress.

Learn more biomedcentral.com/submissions 